\title{
The Impact Of American Advertising Humor On Taiwanese Consumers
}

Yu Yao Chang, Lamar University, USA

Soumava Bandyopadhyay, Lamar University, USA

\begin{abstract}
This paper examines the effect of American humorous advertising on consumers in Taiwan. Several American print advertisements for brands familiar in Taiwan were shown to Taiwanese consumers in a field study. Three distinct perceptual appeals-humor, quality and positivity-in the processing of the advertisements by Taiwanese consumers were identified. It was found that all of these three types of appeals positively impacted the perceived image of and the motivation to purchase the brands featured in the advertisements. This paper also discusses the managerial implications and future research avenues stemming from the results of the study.
\end{abstract}

Keywords: Advertising; Humor Appeal; Brand Image; Purchase Motivation; Taiwan

\section{INTRODUCTION}

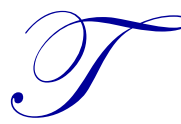

(Weinberger \& Campbell, 1991). As a result, humorous content is now present in a large percentage of advertisements across different media platforms.

Culture has a strong influence on the perception of humor (Lee \& Lim, 2008). What is perceived as funny in one culture might be seen as offensive in another. There is evidence, however, that humorous communications from cultures as diverse as North America, Europe, and Asia share certain universal structures underlying the message (Alden, Hoyer, \& Lee, 1993). These universal elements are the focus of global advertising campaigns that are centered on the humor appeal. These elements permit the transference of humorous advertisements from one country to another with similar effectiveness.

In this paper, we report an empirical study to examine the effect of American humorous advertisement on consumers in Taiwan. Cross-cultural studies on the use of humor in advertising have been conducted in countries such as the United Kingdom (Weinberger \& Spotts, 1989), Germany, South Korea, Thailand (Alden, Hoyer, \& Lee, 1993), and Singapore (Pornpitakpan \& Tan, 2000). No study has been reported, however, on Taiwanese consumers' processing of American humorous advertisements, and this paper seeks to fill that gap. Taiwan has one of the highest per capita GDPs among Asian countries at \$39,400 after purchasing power parity (PPP) adjustment (Central Intelligence Agency, 2013), and is regarded as one of the advanced economies of the world. The high consumer purchasing power makes Taiwan an attractive market for global companies who would naturally be interested in the possible transference of successful advertising campaigns from other countries into Taiwan.

\section{LITERATURE REVIEW}

Three types of humor mechanisms that can be used in advertising have been identified in the literature: cognitive, affective, and social/interpersonal (Unger, 1995; Lee \& Lim, 2008). The key to cognitive humor is incongruity, or deviation from expectations (Alden, Hoyer, \& Lee, 1993). Some researchers argue that incongruity is a necessary and sufficient condition to produce humor (Suls, 1983) and the humor response is proportional to the degree of deviation from normally expected occurrences (Nerhardt, 1970). Other researchers maintain that 
incongruity resolution, rather than incongruity alone is needed to produce a humor response (Alden, Hoyer, \& Lee, 1993). This means that humor is a form of problem solving. In advertisements, the problem-solving should be depicted in a "playful" context, where the cues signifying the resolution should not be taken seriously (Suls, 1983). Alden, Hoyer, and Lee (1993) observed that incongruity resolution appeared to be present in much of the humor around the world, and hence it might be a major component of global humorous advertising.

In the affective approach, perceived humor is determined by physiological arousal and thematic content, such as sex, aggression, and freedom (Cho, 1995). The driving force of humor is the effort to reach an optimal level of arousal through the advertising message. Advertisers use either arousal-raising components, such as surprise, or arousal-relieving components, such as pleasant mood.

The social/interpersonal approach tries to explain humor in terms of the social and interpersonal contexts within which humor occurs (Cho, 1995). The social/interpersonal approach in advertising requires advertisers to focus on values shared among the target audience and sublimated themes in their culture. Because of the cultural dependence of the social/interpersonal approach, this mechanism is likely to be the most determining factor in perceived humor within a particular culture (Alden, Hoyer, Lee \& Wechasara, 1995).

Researchers have also studied how humor is processed and when humor actually occurs (Woltman-Elpers, Mukherjee, \& Hoyer, 2004). Alden, Mukherjee, and Hoyer (2000) have suggested a two-stage theory of humorprocessing. According to this theory, an ad first generates surprise, which is subsequently transformed into humor. The extent of the surprise and the subsequent humor is dependent on the degree to which the content of the ad differs from the consumers' attitudes, beliefs, and behaviors. Consumers' acceptable attitudes, beliefs, and behaviors are largely guided by their cultural environments (Zhang \& Gelb, 1996). Therefore, the processing of ad humor is expected to be grounded in the cultural backgrounds of consumers.

Several studies have been carried out to explore the effects that cultural differences are likely to have on consumer perceptions of and responses to advertising humor. Comparative studies between the United States and a number of Asian countries, such as Singapore (Pornpitakpan \& Tan, 2000), Thailand and South Korea (Alden, Hoyer, Lee \& Wechasara, 1995) have been reported. The results generally prove that although the Western theories of humor processing are applicable to Asian markets, the application of humorous advertising is more widely used in the Western societies.

\section{RESEARCH QUESTIONS}

Based on the observation that the processing of advertising humor is grounded in the cultural environment of the consumers (Zhang \& Gelb, 1996), we have our first research question:

RQ1: What are the different perceptual dimensions that are relevant to the processing of humorous advertisements by Taiwanese consumers?

Employing humor in advertisements is fundamentally based on the belief that humor helps influence audience response to the ad and the advertised product in a direction favorable to the advertiser (Zhang \& Zinkhan, 2006). This includes the consumers' attitude toward the advertised brand (Gardner, 1985) and, subsequently, the consumers' motivation to purchase the brand (MacDonald \& Sharp, 2000). This consideration leads to our second research question:

RQ2: How do the different perceptual dimensions relevant to the processing of humorous advertisements impact brand awareness and purchase motivation in Taiwanese consumers?

\section{RESEARCH DESIGN}

The answers to the research questions were sought via a field study in Taiwan. The sample was a total of one hundred and one undergraduate and graduate students recruited from a large Taiwanese public university located in Taipei. The subjects were shown a total of eight humorous print ads selected from two online articles: 
"140 Funny and Unconventional Print Advertisements" (Icanbecreative.com, 2011), and "30 Hilarious Print Advertisements" (Spyrestudios.com, 2011). In order to maximize the efficacy of the study, the selected ads were for foreign brands that were well known to Taiwanese consumers (by virtue of being easily available in the Taiwanese market). Print ads were selected since Taiwanese consumers tend to spend a great deal of time with print media (La Ferle, Edwards, \& Lee, 2008). The ads are reproduced in the Appendix.

The subjects were given a survey, which showed an ad on each page, and were asked a number of questions relating to their perceptions of each ad. For each ad, sixteen survey items asked about the subjects' perceived humor from and attitude toward the ad on a 7-point semantic differential scale (the extremities being amusing/not amusing, likeable/not likeable, inspiring/not inspiring, etc.). The scale items were adapted from Edell and Burke's (1987) study on feelings towards ads, and Cho's (1995) and Chattopadhyay and Basu's (1990) studies on humor in advertising. There were two additional survey items for each ad-one on the resulting brand image (improve brand image/worsen brand image on a 7-point semantic differential scale), and the other on the resulting motivation to purchase the brand (increased purchase motivation/decreased purchase motivation) on a 7-point semantic differential scale) after viewing the ad.

The 101 subjects were gathered together in a large classroom to complete the survey. They were dismissed individually after completing the survey.

\section{RESULTS}

\section{Sample Demographics}

Of the 101 respondents, 69 (68.3\%) were female. The average age was 20.9 years. The average number of hours spent reading print media was 3.60 hours per week, which was about the same as the average time spent watching television ( 3.55 hours per week). The relatively young sample would make one expect a high amount of time spent on the Internet, which was found to be true at 23.3 hours per week.

\section{Perceptual Dimensions in the Processing of Humorous Ads}

An exploratory factor analysis of the 16 scale items related to the perceived humor and feelings after viewing the ads was conducted. The average measures from across all the eight ads were considered. The factor analysis revealed three principal components with Eigenvalues greater than 1.0, accounting for 77.4 percent of the variance in the scores. The varimax-rotated factor loadings are shown in Table 1.

An examination of the three factors led us to name them in accordance with the three distinctly emerging perceptual appeals:

1. Humor Appeal: This factor included perceptions related to the humor mechanism in the ads, such as the ads being perceived as amusing, having a good sense of humor, likeable, not irritating, interesting, original, easy to understand, and surprising. The humor appeal factor consisted of eight items.

2. Quality Appeal: This factor captured perceptions relating to the quality of the ads. Five items were included in this factor, which were the ads being perceived as not offensive, friendly, having a good expression, not discriminatory, and not sarcastic.

3. Positivity Appeal: This factor included perceptions related to how positively the ads were perceived, such as being inspiring, superior, and stimulating. This factor comprised of three items.

Next, a Cronbach's Alpha reliability analysis was conducted to test the internal consistency of the items in the three factors. The results appear in Table 2. It is seen that all three factors had acceptable Cronbach's Alpha values, at .862 and above. 
Table 1: Loadings of Perceptual Dimensions of Ads on Varimax-Rotated Principal Components $(\mathrm{N}=101)$

\begin{tabular}{|c|c|c|c|}
\hline $\begin{array}{l}\text { Perceptual Dimensions } \\
\end{array}$ & Humor Appeal & Quality Appeal & Positivity Appeal \\
\hline The ads are amusing & .850 & & \\
\hline The ads have a good sense of humor & .826 & & \\
\hline The ads are likeable & .677 & & \\
\hline The ads are not irritating & .653 & & \\
\hline The ads are interesting & .715 & & \\
\hline The ads are original & .750 & & \\
\hline The ads are easy to understand & .550 & & \\
\hline The ads are surprising & .787 & & \\
\hline The ads are not offensive & & .789 & \\
\hline The ads are friendly & & .750 & \\
\hline The expressions in the ad are good & & .681 & \\
\hline The ads are not discriminatory & & .809 & \\
\hline The ads are not sarcastic & & .909 & \\
\hline The ads are inspiring & & & .723 \\
\hline The ads are superior & & & .809 \\
\hline The ads are stimulating & & & .771 \\
\hline Eigenvalue & 9.652 & 1.705 & 1.027 \\
\hline Percentage of Variance Explained & 60.32 & 10.66 & 6.42 \\
\hline Cumulative Percentage of Variance Explained & 60.32 & 70.98 & 77.40 \\
\hline
\end{tabular}

Table 2: Reliability Analysis of the Emerging Perceptual Dimensions

\begin{tabular}{|l|c|c|}
\hline \multicolumn{1}{|c|}{ Dimension } & Number of Items & Cronbach's Alpha \\
\hline Humor Appeal & 8 & .930 \\
\hline Quality Appeal & 5 & .936 \\
\hline Positivity Appeal & 3 & .862 \\
\hline
\end{tabular}

\section{Impact of Perceptual Dimensions on Brand Image and Purchase Motivation}

The impact of the three perceptual dimensions of the ads on the perceived brand image and the motivation to purchase the advertised brand was examined via regression analysis. First, the measured improvement in perceived brand image after viewing the ads were regressed on the three perceptual dimensions of humor appeal, quality appeal, and positivity appeal. The results are indicated in Table 3. The overall regression model with the three predictor variables was found to be statistically significant $(\mathrm{F}=79.33$ with 3 degrees of freedom, $\mathrm{p}<.001)$, with $\mathrm{R}^{2}=.735$. All three perceptual dimensions, humor appeal (standardized $\beta=.189, \mathrm{t}=2.34$, $\mathrm{p}<.05$ ), quality appeal (standardized $\beta=.303, \mathrm{t}=3.73, \mathrm{p}<.001$ ), and positivity appeal ( standardized $\beta=.462, \mathrm{t}=5.14, \mathrm{p}<.001$ ) were found to positively and significantly impact the perceived improvement in brand image.

Next a regression analysis was made with the perceived increase in motivation to purchase the advertised brand as the dependent variable, and the three perceptual dimensions as the independent variables. The results of this regression are shown in Table 4. Again, the overall regression model with the three predictor variables was found to be statistically significant $(\mathrm{F}=69.03$, with 3 degrees of freedom, $\mathrm{p}<.001)$, with $\mathrm{R}^{2}=.707$. Also, all the three perceptual dimensions, humor appeal (standardized $\beta=.325, \mathrm{t}=3.81, \mathrm{p}<.001$ ), quality appeal (standardized $\beta=$ $.286, \mathrm{t}=3.35, \mathrm{p}<.001$ ), and positivity appeal (standardized $\beta=.337, \mathrm{t}=3.56, \mathrm{p}<.001$ ) were found to positively and significantly affect the perceived increase in purchase motivation.

Table 3: Regression Predicting Perceived Improvement in Brand Image

\begin{tabular}{|c|c|c|}
\hline \multicolumn{3}{|l|}{$\begin{array}{l}\text { Number of Observations }=101 \\
\mathrm{R}^{2}=.735 \\
\text { Overall } \mathrm{F}=79.33 \text {, d.f. }=3, \mathrm{p}<.001\end{array}$} \\
\hline $\begin{array}{l}\text { Predictor Variable } \\
\end{array}$ & Standardized $\beta$ Coefficient Estimate & t-Value (Probability of $t$ ) \\
\hline Intercept & 0.00 & $-1.52(\mathrm{p}=.13)$ \\
\hline Humor Appeal & .189 & $2.34(\mathrm{p}<.05)$ \\
\hline Quality Appeal & .303 & $3.73(\mathrm{p}<.001)$ \\
\hline Positivity Appeal & .462 & $5.14(\mathrm{p}<.001)$ \\
\hline
\end{tabular}


Table 4: Regression Predicting Perceived Increase in Purchase Motivation

\begin{tabular}{|c|c|c|}
\hline \multicolumn{3}{|c|}{$\begin{array}{l}\text { Number of Observations }=101 \\
\mathrm{R}^{2}=.707 \\
\text { Overall } \mathrm{F}=69.03 \text {, d.f. }=3, \mathrm{p}<.001\end{array}$} \\
\hline Predictor Variable & Standardized $\beta$ Coefficient Estimate & t-Value (Probability of t) \\
\hline Intercept & 0.00 & $-2.40(p=.02)$ \\
\hline Humor Appeal & .325 & $3.81(\mathrm{p}<.001)$ \\
\hline Quality Appeal & .286 & $3.35(\mathrm{p}<.001)$ \\
\hline Positivity Appeal & .337 & $3.56(\mathrm{p}<.001)$ \\
\hline
\end{tabular}

\section{DISCUSSION AND MANAGERIAL IMPLICATIONS}

The results from the field study in Taiwan provided answers to both our research questions. First, three different perceptual dimensions in the processing of humorous advertisements by Taiwanese consumers were identified: humor appeal, quality appeal, and positivity appeal. Second, all three perceptual dimensions relevant to the processing of humorous advertisements positively impacted perceived brand image and purchase motivation.

The clear emergence of the three perceptual dimensions with high internal consistencies among the constituent items (evidenced by the high Cronbach's Alphas) indicates the positive manner in which American humorous ads affect Taiwanese consumers. This supports the premise that humor is universal (Alden, Hoyer, \& Lee, 1993). The cultural inclination of the consumers is likely to have an influence on the understanding and appreciation of humor transferred from another culture as well. In our study, a dominant percentage of the subjects (93.8\%) reported that they had no living experience in the U.S., and were born and raised in Taiwan. However, $92.1 \%$ of the subjects indicated that they either preferred Chinese and American movies equally, or preferred American movies only. In addition, $44.5 \%$ of the subjects rated themselves as at least somewhat influenced by American culture. These numbers reflected a moderate level of social and cultural westernization in Taiwan, which is likely to have assisted in the positive interpretation of American humorous ads.

The regression analyses (Tables 3 and 4) show that the humor appeal in ads is not alone in generating an improved brand image and purchase motivation. The quality appeal and the positivity appeal also play a significant role in the outcomes that matter to marketers in the end (i.e., brand image and purchase motivation). In fact, when it comes to the perception of an improved brand image, the quality appeal and the positivity appeal play a relatively greater role than humor appeal by itself (Table 3). Advertisers seeking to successfully transfer American humorous ads to the Taiwanese market should keep this in mind-the ads should contain the values related to the quality and positivity appeal and should be perceived as adequately friendly, stimulating, and inspiring and should not be perceived as offensive, discriminatory, or sarcastic.

Standardization of marketing strategies is always desirable in a global marketplace because of the costsaving benefits. Duncan and Ramaprasad (1995) defined standardization of advertising as keeping at least one of the three essential components of a multinational advertising campaign the same. These three components are: strategy (the creative selling proposition), execution (the actual elements and their structure in ads), and language. The language is usually changed to the local one for better comprehension purposes. In our study, the ads had very little linguistic component (see Appendix) and relied mostly on visual appeal generated by strategy and structure. In transferring ads containing a greater amount of text copy, marketers will need to be careful about properly translating or localizing the copy.

\section{FUTURE RESEARCH}

Future research could fine tune the study by broadening the sampling scope to include older Taiwanese consumers. Older consumers are less likely to be as influenced by American culture as the subjects in our study (who were college students with an average age of 20.9 years) and, therefore, the successful transfer of American humorous ads may pose more of a challenge with these consumers. 


\section{AUTHOR INFORMATION}

Mr. Yu Yao Chang has graduated from the MBA program at Lamar University, USA. In his graduate studies, he concentrated in the areas of services management and marketing. His research interests include strategic marketing and global marketing. E-mail: veloluz1@gmail.com

Dr. Soumava Bandyopadhyay is a professor of marketing, and Jerry and Sheila Reese Faculty Scholar in Business at Lamar University, USA. His areas of research interest include Internet-based marketing, global marketing, and channels of distribution. E-mail: soumava.bandyopadhyay@lamar.edu (Corresponding author)

\section{REFERENCES}

1. Alden, D. L., Hoyer, W. D., \& Lee, C. (1993). Identifying global and culture-specific dimensions of humor in advertising: A multinational analysis. Journal of Marketing, 57(April), 64-75.

2. Alden, D. L., Hoyer, W. D., Lee, C., \& Wechasara, G. (1995). The use of humor in Asian and Western television advertising: A four country comparison. Journal of Asia-Pacific Business, 1(2), 3-23.

3. Alden, D. L., Mukherjee, A., \& Hoyer, W. D. (2000). The effects of incongruity, surprise, and positive moderators of perceived humor in television advertising. Journal of Advertising, 29(Summer), 1-15.

4. Chattopadhyay, A., \& Basu, K. (1990). Humor in advertising: The moderating role of prior brand evaluation. Journal of Marketing Research, 27(November), 466-476.

5. Central Intelligence Agency. (2013). The CIA world factbook. New York: Skyhorse Publishing.

6. Cho, H. (1995). Humor mechanisms, perceived humor and their relationships to various executional types in advertising. In F. R. Kardes \& M. Sujan, (eds.). Advances in consumer research (Vol. 22) (pp. 191-197). Provo, UT: Association for Consumer Research.

7. Duncan, T., \& Ramaprasad, J. (1995). Standardized multinational advertising: The influencing factors. Journal of Advertising, 24(3), 55-67.

8. Edell, J. A., \& Burke, M. C. (1987). The power of feelings in understanding advertising effects. Journal of Consumer Research, 14(December), 421-433.

9. Gardner, M. P. (1985). Does attitude toward the ad affect brand attitude under a brand evaluation set? Journal of Marketing Research, 22(May) 192-198.

10. Icanbecreative.com (2011). 140 funny and unconventional print advertisements. Retrieved from http://www.icanbecreative.com/funny-print-ads-advertisements.html

11. La Ferle, C., Edwards, S. M., \& Lee, W. N. (2008). Culture, attitudes, and media patterns in China, Taiwan, and the U.S.: Balancing standardization and localization decisions. Journal of Global Marketing, 21(3), 191-205.

12. Lee, Y. H., \& Lim, E. A. C. (2008). What's funny and what's not: The moderating role of cultural orientation in ad humor. Journal of Advertising, 37(2), 71-84.

13. MacDonald, E. K., \& Sharp, B. M. (2000). Brand awareness effects on consumer decision making for a common, repeat purchase product: A replication. Journal of Business Research, 48(1), 5-15.

14. Nerhardt, G. (1970). Humor and inclinations of humor: Emotional reactions to stimuli of different divergence from a range of expectancy. Scandinavian Journal of Psychology, 11(3), 185-195.

15. Pornpitakpan, C., \& Tan, T. K. J. (2000). The influence of incongruity on the effectiveness of humorous advertisements: The case of Singaporeans. Journal of International Consumer Marketing, 12(3), 27-45.

16. Spyrestudios.com (2011). 30 Hilarious Print Advertisements. http://spyrestudios.com/hilarious-print-ads/

17. Suls, J. (1983). Cognitive processes in humor appreciation. In . Goldstein, (ed.). Handbook of humor research (pp. 39-57). J New York: Springer Verlag.

18. Unger, L. S. (1995). Observations: A cross-cultural study on the affect-based model of humor in advertising. Journal of Advertising Research, 35(January-February), 66-71.

19. Weinberger, M. G., \& Campbell, L. (1991). The use and impact of humor in radio advertising. Journal of Advertising Research, 30(December/January), 44-51.

20. Weinberger, M. G., \& Spotts, H. E. (1989). Humor in U.S. versus U.K. tv advertising. Journal of Advertising, 18(Summer), 39-44.

21. Woltman-Elpers, J. L. C. M., Mukherjee, A., \& Hoyer, W. D. (2004). Humor in television advertising: A moment-to-moment analysis. Journal of Consumer Research, 31(December), 592-598. 
22. Zhang, Y., \& Gelb, B. (1996). Matching advertising appeals to culture: The influence of products' use conditions. Journal of Advertising, 25(Fall), 29-46.

23. Zhang, Y., \& Zinkhan, G. M. (1991). Humor in television advertising: The effect of repitition and social setting. In R. H. Holman \& M. R. Solomon (eds.). Advances in Consumer Research (Vol. 18) (pp. 813818). Provo, UT: Association for Consumer Research.

24. Zhang, Y., \& Zinkhan, G. M. (2006). Responses to humorous ads: Does audience involvement matter? Journal of Advertising, 35(Winter), 113-127. 


\section{APPENDIX}

Print Ads Used in the Study

(Source: Icanbecreative.com and Spyrestudios.com)

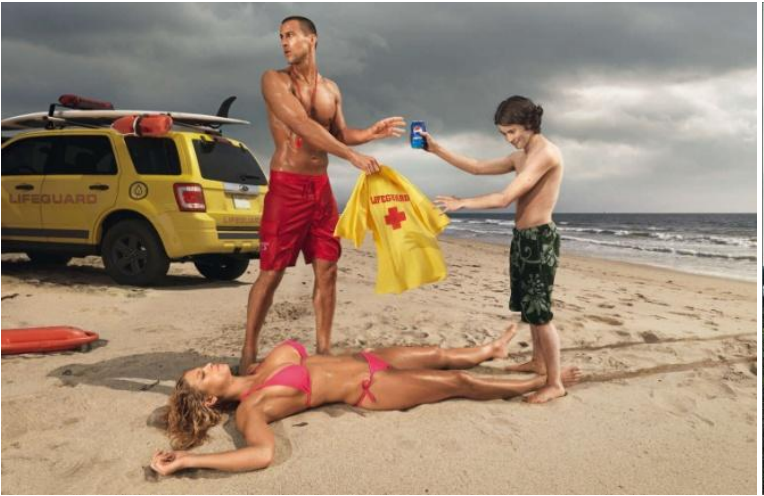

Brand: Pepsi

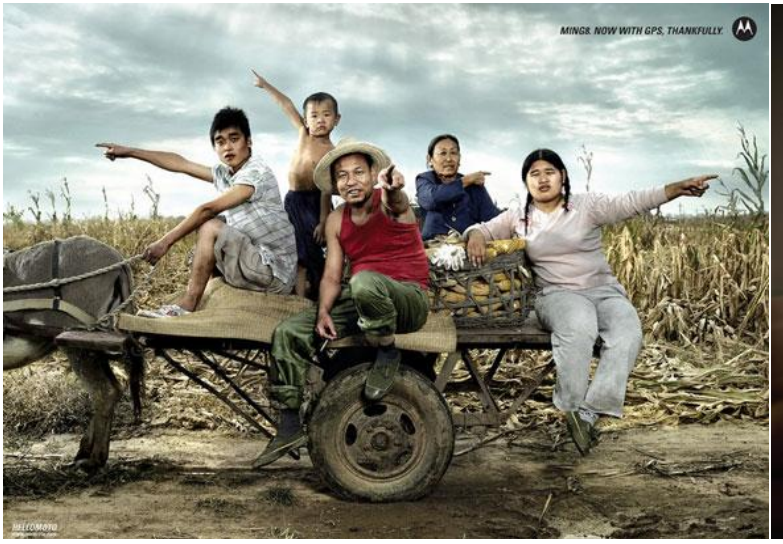

Brand: Motorola

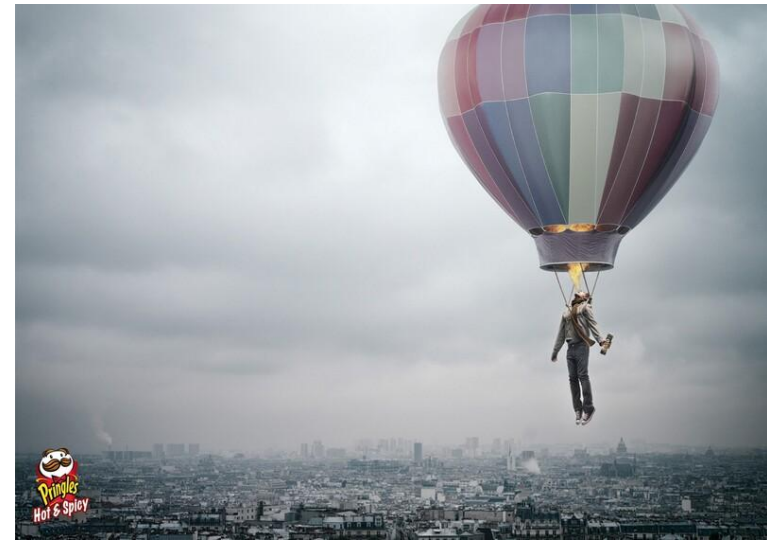

Brand: Pringles

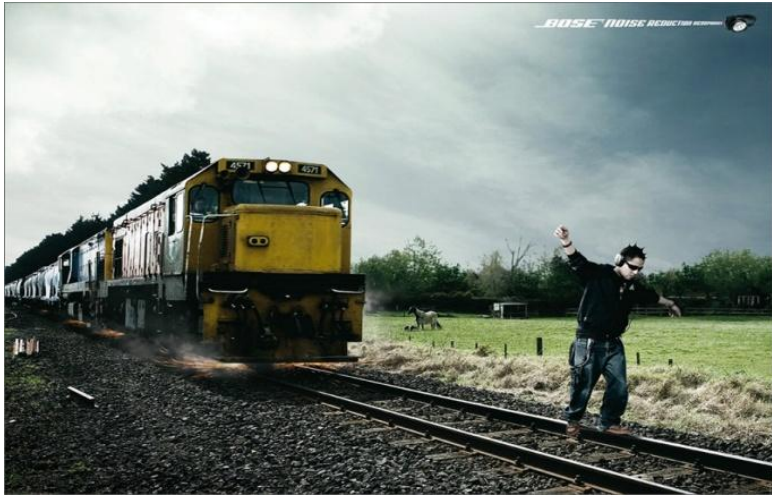

Brand: Bose

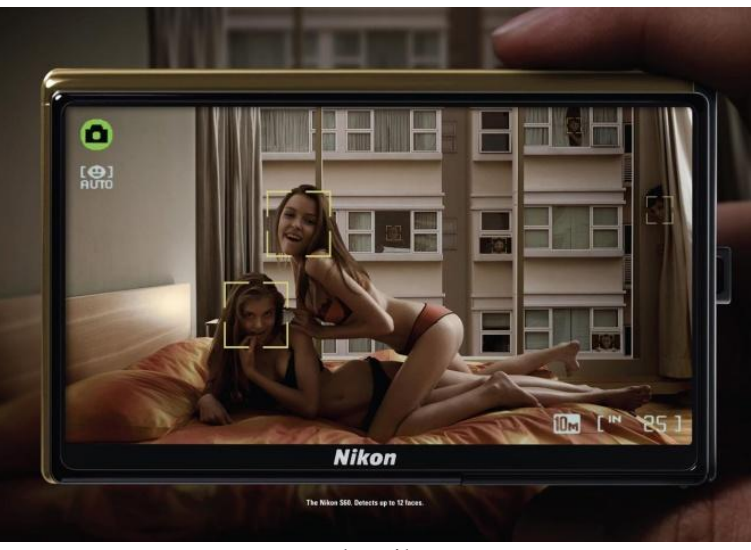

Brand: Nikon

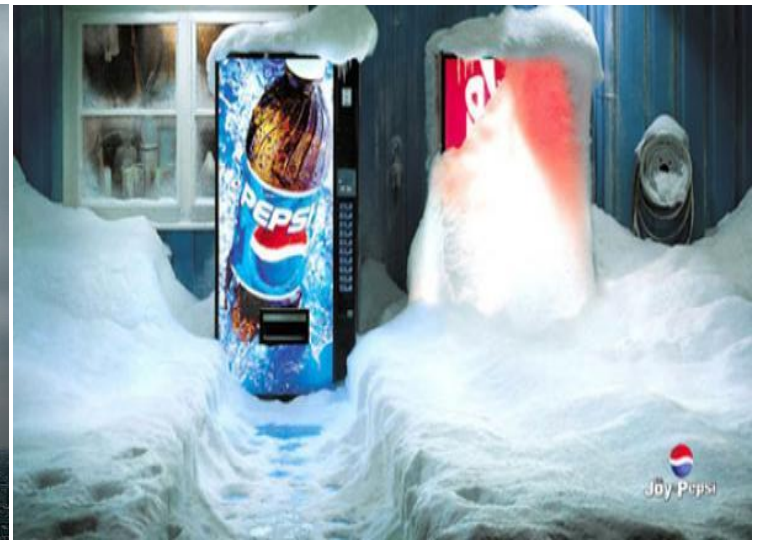

Brand: Pepsi 


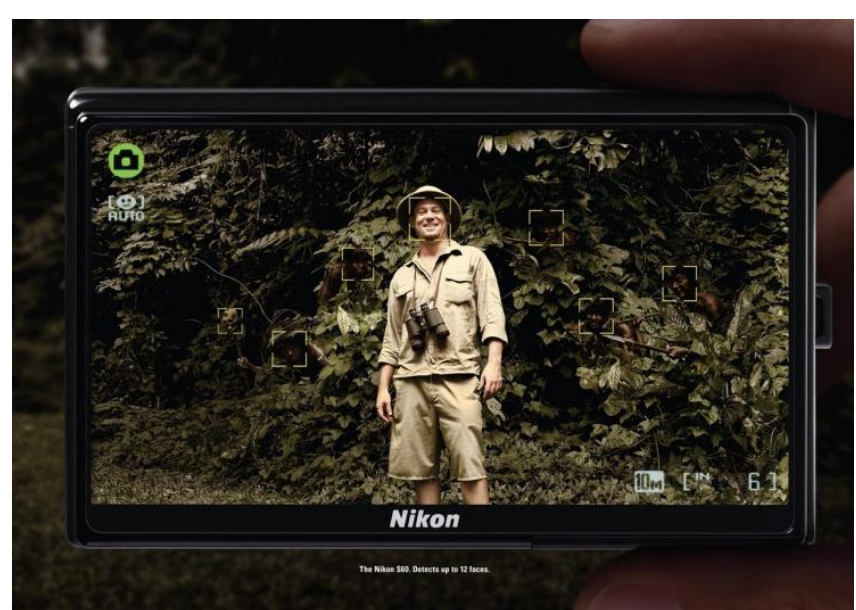

Brand: Nikon

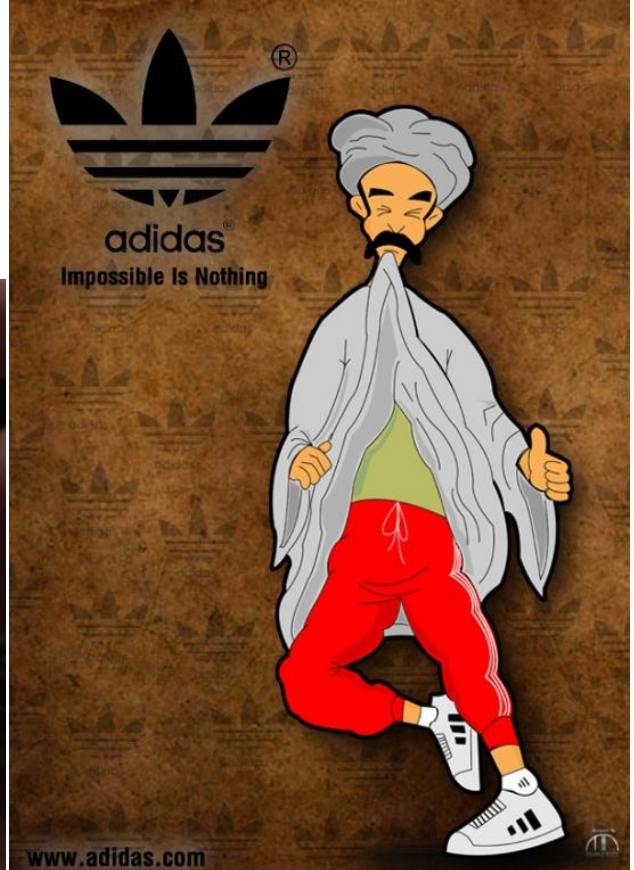

Brand: Adidas 


\section{NOTES}

